\title{
Computational Chemistry Statistics
}

National Cancer Institute

\section{Source}

National Cancer Institute. Computational Chemistry Statistics. NCI Thesaurus. Code C19399.

Statistics associated with computational chemistry. 